\title{
EXPERIENCES IN THE DEVELOPMENT OF A SUSTAINABLE SCORECARD FOR ENTERPRISE SUSTAINABILITY COURSE
}

\author{
Ricardo Chalmeta, Manuel Mollar, Guillermo Peris \\ Grupo de Integración y Re-ingeniería de Sistemas. Dept. Lenguajes y Sistemas \\ Informáticos. Universitat Jaume I (SPAIN)
}

\begin{abstract}
The Universitat Jaume I (UJI) of Castellón, Spain and the National Distance Education University (UNED) are teaching together the Master's Degree in Corporate Sustainability and Social Responsibility. The main objective is to study the concepts of sustainability and corporate social responsibility (CSR) and their multiple dimensions. This master's degree aims to train professionals to practically apply the approach of ethics, sustainability and social and environmental responsibility to existing business models, and to other public and private organizations, such as not-for profit organizations and government public bodies.
\end{abstract}

The master is composed of different courses. One of them is focused in how to build a sustainable scorecard to support enterprise sustainability decisions making. A sustainable scorecard is a performance measurement and management system aiming at balancing financial and non-financial as well as short and long-term measures. It is one of the most effective tools in evaluating potential investments and initiatives by better integration of the environmental, social and economic aspects of corporate sustainability measurement and management.

The sustainable scorecard for enterprise sustainability course equips students with the necessary basic knowledge and competencies they need to design and utilize a sustainable scorecard for enterprise management, considering not only technological aspects, but also the management of organization policies and people.

The aim of this paper is to describe the subject objectives, the target competencies, the subject contents, the assessments, and how the teaching methodology and the resources are used to teach the subject.

Keywords: Corporate Sustainability and Social Responsibility, balanced scorecard, learning experiences, curriculum design.

\section{INTRODUCION}

The Balanced Scorecard (CMI) constitutes one of the most effective management control tools to implement and put into practice the strategic plan of a Company. The BSC provides "a framework that translates strategy into action" which is organised around four perspectives (Financial, Customers, Processes and Training). It is based on a set of financial and non-financial indicators derived from the strategy that provide relevant information on the company's situation in different areas such as finance, customers, employees, processes, etc.

Among the most important benefits of using a Balanced Scorecard are:

- It allows having a comprehensive vision of the business.

- Facilitates the communication, execution, and implementation of the strategy.

- Assign responsible people to the objectives.

- Motivate employees.

- Evaluate and adjust the strategy and action plans.

- Measure improvements in operations efficiency.

The balanced scorecard is being widely used in companies and administrations of medium and large size and is increasingly being implemented in those of small size.

However, one of the main challenges currently existing for the management of companies that want to implement a sustainability strategy [1] is the need to expand and balance their scorecards, so that in 
addition to the classic indicators, they include others that provide more information on the future of the company and its impact on social and environmental aspects $[2,3]$. In this way, it will be possible to verify if the strategic objectives of sustainability are being achieved and, if not, take the appropriate decisions to achieve them.

Several authors have pointed at opportunities to develop the well-established Business Balanced Scorecard (BSC), proposed by [4] in 1996, into a Scorecard that enables companies to integrate sustainability into their strategy.

Therefore, students of the Master's Degree in Corporate Sustainability and Social Responsibility needs to know how to include the dimensions of ecological and social sustainability within corporate strategic considerations and how to manage them using the BSC.

This paper describes the sustainable scorecard for enterprise sustainability course of the Master's Degree in Corporate Sustainability and Social Responsibility at the Universitat Jaume I (UJI) of Castellón, Spain and the National Distance Education University (UNED). It shows the target competencies, the course contents, the assessments, and how the teaching methodology and the resources are used to teach the subject.

\section{OBJECTIVES}

The objective of the course is to show students a tool that enables them to design and implement a sustainability scorecard in business organisations day-to-day management, integrating the social and environmental concepts within the management models.

Therefore, the course shows students the process and steps of formulating a Sustainability Balanced Scorecard. A Sustainability Balanced Scorecard is a Balanced Scorecard (BSC) that integrates the three dimensions of sustainability - economic, environmental and social - simultaneously. To do this, a mix of the methodologies showed in $[5,6]$ are followed.

\section{LEARNING OUTCOMES/CAPABILITY DEVELOPMENT}

\subsection{Specific capabilities}

- To understand how information and information systems relate in the total enterprise for strategic Sustainability decisions

- To build and implement Sustainability balanced scorecard planning and management systems

- To develop Communications strategy and change management of the Sustainability balanced scorecard

- To select appropriate software to collect and report Sustainability information throughout the organization

- To cascade the Sustainability scorecard throughout the organization

\subsection{Cognitive Capabilities}

- Computer literacy

- Analytic/design (conduct research, analyse, reason, solve problems, interpret data)

- Appreciative (evaluate ideas, make judgements, think critically, multidisciplinary perspectives, self-recognition)

\subsection{Behavioural Capabilities}

- Personal (think and act independently, creativity, tolerant of ambiguity, flexible)

- Interpersonal (listening, presentation, communicate, negotiate, group dynamics, collaboration) 


\section{LEARNING METHODOLOGY}

Learning methodology uses Active Learning. Active Learning involves students directly and engages them actively in the learning process itself. Students are involved in all stages of planning, design, execution and evaluation.

Active Teaching Methods used in the course are Group projects, Questionnaires, Practical work, Brainstorming, Group discussion, Case studies, Sharing experiences, Group work.

Active Teaching Methods used Out of School are: Surveys, Market research, Questionnaire design

\section{SYLLABUS/COURSE CONTENT}

\subsection{Active Learning}

The main objective of the active learning is that students apply the methodologies showed in [5] and [6] to an organization. They have to do it in groups composed by 5 students. The methodologies are organised in phases and outlines the activities to be performed, the techniques and supporting tools to be used, and the expected results for each phase.

So, the students have to carry out the following activities to develop a Sustainability balanced scorecard in an organization:

\subsubsection{Phase l: Project Planning}

It is the initial phase for the development of the project. The scope and organizational unit where the project will be applied are identified. In this phase, in addition, the team to carry out the project is created as well as a leader and a project coordinator are appointed. Specialists in finance, human resources, information technology, and quality must be part of the team, and members of different areas of the unit/company must also participate. Therefore, the main tasks during this stage are: Creation of teams for the development of the CMI project; Training seminars for the development and implementation of the project; Preparation and communication of the project plan; Establish quality control mechanisms; and Develop the plan for change.

\subsubsection{Phase II: Strategic Balanced Scorecard Design}

The purpose of this phase is to express the company strategy through a system of indicators that clarify and define the strategic objectives of the organization, through an integrated and balanced set of objectives and indicators broken down in six perspectives: Financial, Clients, Processes, Technology, Training, and Social. The indicators constitute a measure to evaluate and control the proposed objectives. There are several criteria for selecting an indicator [7]:

- They must measure the objectives to be met by the strategy

- They must be expressed quantitatively

- The relationship between them must indicate the fulfilment of a set of objectives

- Its meaning must be easy to understand by the organization

- They must be defined in a template with their characteristics

\subsubsection{Phase III: Process Design and Improvement}

Once the organizational framework, business strategy, and its objectives and indicators have been defined at different perspectives, it is necessary to improve the business processes. The analysis of business processes with a view to achieving compliance with the business strategy will facilitate the improvement of the results of the proposed indicators. To do this, it is necessary to identify the processes and the activities of each one of them, and to build the process map where the current situation is analyzed (AS-IS), and the future processes (TO-BE) are designed. For each one the activities that are carried out in a project, a list of deficiencies and improvement plans must be identified.

On tool to employ is the process modelling. The modelling of current processes is of great importance for the redesign of processes, the implementation of continuous improvements, and the effective management of business processes. The process modelling can indicate the set of activities, inputs, outputs, procedures and controls so that the quality, efficiency and effectiveness of each process can 
be evaluated to carry out the project of the improvement plan. Examples of how to do this can be found in $[8,9,10,11]$.

\subsubsection{Phase IV: Deployment of the Scorecard by business units and Validation}

In this phase, the CMI deploys the organizational strategy through all hierarchical levels of the company. At each level, a procedure similar to phase 2 can be followed, based on the objectives set by senior management.

Each unit and person in the organization must know how their work affects the strategic objectives and negotiate with their superiors the indicators that will be used to assess the results of their efforts. This can be indicated by the diagram that establishes the cause-effect indicators relationship.

The validation of the indicators must take into account both the degree of fulfilment of the criteria defined to select them and their validity as a support in decision-making. One way to validate them is to estimate them subjectively by analysing similar indicators from companies within the company sector.

In addition, in this phase of the Sustainability Scorecard project, the students have to design the information and communications infrastructure that is capable of extracting the data for calculating the indicators, processing them and communicating them. It should be pointed out, as suggested by some authors, that this is one of the main obstacles preventing enterprises from having an adequate Sustainability Scorecard. The support information system uses the information contained in a data warehouse, which is extracted from business-specific systems tools such as ERP (Enterprise Resource Planning), CRM (Customer Relationship Management), or SCM (Supply Chain Management), which are a mixture of operational and strategic systems since they allow making decisions about marketing, orders, prices, etc. From this integrated data, models are generated for the analysis of the organization with useful data mining tools for analysis, financial, customer, market, etc.

OLAP (On-Line Analytical Processing) technical tools that transform data into strategic information are also integrated as part of the system, which helps decision-making, in this case using the data warehouse, as well as the indicator databases. .

The use of Web and Workflow tools for e-business together with the rise of the Internet allows access to information from anywhere and assign tasks and information to participants and those responsible for business processes. Examples of how to do this can be found in [12, 13].

\subsubsection{Phase VIII: Implementation of the Sustainability Scorecard}

People in a company are the key to any business strategy and to determine the success or failure of the Sustainability Scorecard. Therefore, the aim of this phase is to ensure that all members of the organisation are familiar with the Sustainability Scorecard project. Training courses for enterprise employees have to be designed by the students.

\section{ASSESSMENT}

The assessment of this course is carried out through two different items: The assessment of the Group project developed by the students to obtain a Sustainability balanced scorecard in an organization; and an individual final exam. The assessment percentage of each part is as follows:

Group work: $50 \%$

Test: $50 \%$

\section{CONCLUSIONS}

This paper shows the curriculum design and the development of a Sustainable Scorecard for Enterprise Sustainability Course. Students are very satisfied with course contents and organization. The course is focused in practical work, so theory can be understood easier, and students obtain new knowledge and new skills, similar to professional work.

The approach used in teaching this course, with both business and technical backgrounds, enhances students' learning and simulates what these students will encounter when they join the workplace. The project-driven approach used in this course offers additional learning opportunities. Students learn about business value of the IS solution, and they appreciate the challenges of implementing an 
information system solution. This method allowed students to work in teams and helped them develop interpersonal and communication skills. The students also developed trust and respect for both disciplines represented in the course.

\section{REFERENCES}

[1] Commission of the European Communities, (2001). Brussels COM (2001) 366.

[2] Figge, K., Hahn, T., Schaltegger, S., Wagner, M., (2002). The sustainability balanced corecard linking sustainability management to business strategy. Business Strategy and the Environment 11, 269-284.

[3] Van der Woerd, F., Van den Brink, F., (2004). Feasibility of a Responsive Business Scorecard _a pilot study Journal of Business Ethics 55: 173_186

[4] Kaplan R, Norton D. 1996. The Balanced Scorecard: Translating Strategies into Action. Harvard Business School Press: Boston, MA.

[4] Chalmeta, R. \& Palomero, S. (2011) Methodological proposal for business sustainability management by means of the Balanced Scorecard. Journal of the Operational Research Society 62: 1344.

[5] León, R., Muñoz, M.J., Chalmeta, R., 2010. Methodology for Sustainability Strategic Planning and Management. Industrial Management and Data Systems 110 (2) pp. 249-268

[6] Chalmeta, R., Palomero, S., Matilla, M., 2011. Methodology to develop a performance measurement system in small and medium-sized enterprises, International Journal of Computer Integrated Manufacturing, 25:8, 716-740

[7] Lohman, C. Fortuin, L., and Wouters, M., 2004. Designing a performance measurement system: a case study. European Journal of Operational Research, 156(2), 267-286

[8] Orenga-Rogla, S., Chalmeta, R., (2019). Methodology for the Implementation of Knowledge Management Systems 2.0: A Case Study in an Oil and Gas Company. Business \& Information Systems Engineering, 61(2) 195-213

[9] Palomero, S.; Chalmeta, R. (2014). A guide for supply chain integration in SMEs. Production Planning \& Control 25(5) 372-400

[10] Chalmeta, R., Pazos, V. (2015) A step-by-step methodology for enterprise interoperability projects. Enterprise Information Systems (4)9 436-464

[11] Pazos Corella, V., Chalmeta R., Martinez Simarro, D. (2013). SCIF-IRIS framework: a framework to facilitate interoperability in supply chains. International Journal of Computer Integrated Manufacturing, 26 (1-2) 67-86

[12] Orenga-Rogla, S., Chalmeta, R., (2019). Framework for Implementing a Big Data Ecosystem in Organizations. Communications of the ACM, 62(1) 58-65

[13] Matos, G., Chalmeta, R., Coltell, O. (2006). Metodología para la Extracción del Conocimiento Empresarial a partir de los Datos. Información tecnológica 17(2) 81-88 